\title{
RESEARCH
}

Open Access

\section{The 'Eat Well @ IGA' healthy supermarket randomised controlled trial: process evaluation}

Miranda R. Blake ${ }^{1 *} \mathbb{D}$, Gary Sacks ${ }^{1}$, Christina Zorbas ${ }^{1}$, Josephine Marshall1', Liliana Orellana ${ }^{2}$, Amy K. Brown $^{3}$, Marj Moodie ${ }^{1,4}$, Cliona Ni Mhurchu ${ }^{5}$, Jaithri Ananthapavan ${ }^{1,4}$, Fabrice Etilé ${ }^{6}$ and Adrian J. Cameron ${ }^{1}$

\begin{abstract}
Background: Successful implementation and long-term maintenance of healthy supermarkets initiatives are crucial to achieving potential population health benefits. Understanding barriers and enablers of implementation of realworld trials will enhance wide-scale implementation. This process evaluation of a healthy supermarket intervention sought to describe (i) customer, retailer and stakeholder perspectives on the intervention; (ii) intervention implementation; and (iii) implementation barriers and enablers.

Methods: Eat Well @ IGA was a 12-month randomised controlled trial conducted in 11 Independent Grocers of Australia (IGA) chain supermarkets in regional Victoria, Australia (5 intervention and 6 wait-listed control stores). Intervention components included trolley and basket signage, local area and in-store promotion, and shelf tags highlighting the healthiest packaged foods. A sequential mixed-methods process evaluation was undertaken. Customer exit surveys investigated demographics, and intervention recall and perceptions. Logistic mixed-models estimated associations between customer responses and demographics, with store as random effect. Supermarket staff surveys investigated staff demographics, interactions with customers, and intervention component feedback. Semi-structured stakeholder interviews with local government, retail and academic partners explored intervention perceptions, and factors which enabled or inhibited implementation, maintenance and scalability. Interviews were inductively coded to identify key themes.
\end{abstract}

Results: Of 500 customers surveyed, 33\%[95\%Cl:23,44] recalled the Eat Well @ IGA brand and 97\%[95\%Cl:93,99] agreed that IGA should continue its efforts to encourage healthy eating. The 82 staff surveyed demonstrated very favourable intervention perceptions. Themes from 19 interviews included that business models favour sales of unhealthy foods, and that stakeholder collaboration was crucial to intervention design and implementation. Staff surveys and interviews highlighted the need to minimise staff time for project maintenance and to regularly refresh intervention materials to increase and maintain salience among customers.

(Continued on next page)

\footnotetext{
* Correspondence: miranda.blake@deakin.edu.au

'Deakin University, Geelong, Global Obesity Centre, Institute for Health

Transformation, Locked Bag 20000, Victoria 3220 Geelong, Australia

Full list of author information is available at the end of the article
}

(c) The Author(s). 2021 Open Access This article is licensed under a Creative Commons Attribution 4.0 International License, which permits use, sharing, adaptation, distribution and reproduction in any medium or format, as long as you give appropriate credit to the original author(s) and the source, provide a link to the Creative Commons licence, and indicate if changes were made. The images or other third party material in this article are included in the article's Creative Commons licence, unless indicated otherwise in a credit line to the material. If material is not included in the article's Creative Commons licence and your intended use is not permitted by statutory regulation or exceeds the permitted use, you will need to obtain permission directly from the copyright holder. To view a copy of this licence, visit http://creativecommons.org/licenses/by/4.0/ The Creative Commons Public Domain Dedication waiver (http://creativecommons.org/publicdomain/zero/1.0/) applies to the data made available in this article, unless otherwise stated in a credit line to the data. 


\begin{abstract}
(Continued from previous page)
Conclusions: This process evaluation found that interventions to promote healthy diets in supermarkets can be perceived as beneficial by retailers, customers, and government partners provided that barriers including staff time and intervention salience are addressed. Collaborative partnerships in intervention design and implementation, including retailers, governments, and academics, show potential for encouraging long-term sustainability of interventions.
\end{abstract}

Trial registration: ISRCTN, ISRCTN37395231 Registered 4 May 2017.

Keywords: Supermarket, Intervention, Shelf tag, Signage, Process evaluation, Perceptions, Consumer, Australia

\section{Background}

Supermarkets are the leading source of food and beverage purchases globally [1] and are therefore a major influence on population diet and health [2]. The small number of in-store supermarket interventions designed to promote healthier diets ('healthy supermarket initiatives') conducted to date have demonstrated short-term potential to improve the healthiness of consumer purchases by changing aspects of the '4Ps' of marketing: Product, Promotion, Place [3] and/or Price [4, 5] to favour healthier foods and beverages. Population health benefits require such changes to be maintained in the long-term. Understanding the barriers and enablers of successful implementation and maintenance can provide useful information for wide-scale implementation of healthy supermarket initiatives and therefore should be a research priority [6].

The sustainability of healthy supermarket interventions refers to both the maintenance of the intervention and capacity to sustain intervention effects into the future [7]. This may depend on a number of interrelated factors associated with the interventions themselves and the context within which they are implemented. Process evaluations of previous supermarket and grocery store interventions [8-11] have identified barriers to implementation and sustainability that include excessive retailer staff time and resource requirements [9], whereas enablers included perceived high customer satisfaction $[8,9]$ and improved retail brand image [9].

We are not aware of any mixed-methods process evaluations of supermarket initiatives that have considered the perspectives of customers, staff and other key stakeholders together. Critically, previous supermarket interventions and related process evaluations have generally been conducted 3 to 6 months into a project $[8,9,11]$. Process evaluations of supermarket interventions over the longer-term are essential to determine the potential for real-world sustainability and scalability, which relies on changes being maintained and adapted at scale over many months or years.

Here, we conduct an evaluation during and following a 12-month supermarket healthy eating intervention, 'Eat Well @IGA' which aimed to improve the healthiness of customer purchases and increase sales of healthier packaged products and fresh produce. The process evaluation sought to investigate the experiences of customers, staff and stakeholders involved in Eat Well @IGA development and implementation. The objectives were to (i) describe customer, retailer and stakeholder perspectives of the EatWell @IGA intervention; (ii) describe intervention implementation and any variation across intervention sites; and (iii) explore barriers and enablers of implementation.

\section{Methods \\ Overview}

An overview of the development, timelines, and methods used in the Eat Well @IGA project [12] has been previously published [13]. The timeline specific to the process evaluation is shown in Fig. 1.

Briefly, the Eat Well @ IGA project began in 2015 as a series of three short-term retailer-conceived healthy supermarket trials, implemented and evaluated in collaboration with local government and academic partners. The Eat Well @ IGA Randomised Controlled Trial (RCT) was a 12-month, multi-component intervention conducted between May 2017 and May 2018 in 11 Independent Grocers of Australia (IGA) supermarket stores in regional Victoria, Australia (5 intervention and 6 wait-listed control stores). Stores were recruited for RCT participation via the supermarket advertising collective of seven store owners (total 11 stores), which included the supermarkets that participated in the initial shortterm trials. All stores agreed to participate in the intervention and evaluation.

The intervention included three components: (i) signage (trolley and basket signs, floor signs, aisle fins, healthy food posters, and shelf signs ("wobblers")); (ii) local area and in-store promotion (flyers (mailers and in-store), social media, and launch event and related media); and (iii) shelf tags highlighting (healthiest) packaged foods store-wide (defined as all products with 4.5 or 5 stars according to the voluntary governmentendorsed Australian and New Zealand front-of-pack Health Star Rating (HSR) system [14]). The process evaluation of the multi-component intervention is the 


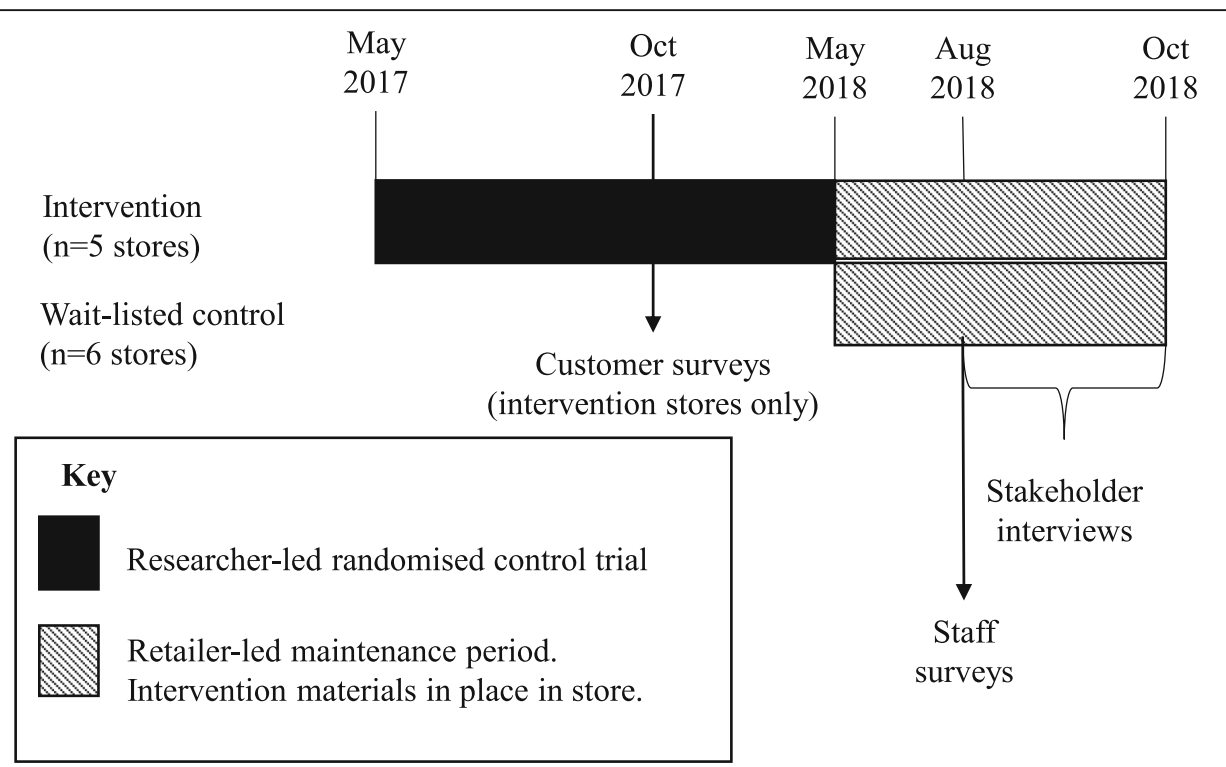

Fig. 1 Timeline of Eat Well @ IGA randomised controlled trial and process evaluation

focus of the current paper. A summary of the results of the EatWell @IGA RCT on supermarket sales has been published separately [13]. Briefly, preliminary results based on multi-level modelling show that the Eat Well @ IGA intervention was associated with slight significant increases in the sales of products with a Health Star Rating of 4.5 or higher, and in sales of fruits and vegetables, but had no significant effect on overall sales of healthy 'core' food according to the Australian Dietary Guidelines [15]. Retailers reported that there was no overall effect of the intervention on profit.

In addition, researchers collected intervention monitoring data to establish the fidelity of implementation (findings to be published in a separate paper alongside changes in supermarket sales). In summary, initial dose of intervention components varied across stores, mainly due to variation in store size. HSR shelf tags and trolley and basket signs were maintained at close to $100 \%$ fidelity throughout the intervention period. Display of posters, aisle fins and shelf wobblers initially increased as store staff gradually implemented all the signage, and then decreased from October 2017 to the end of the official intervention period in May 2018.

A sequential mixed-methods process evaluation was undertaken that included customer surveys (October 2017), staff surveys (August 2018) and qualitative stakeholder interviews (August to October 2018) (Fig. 1).

Customer surveys were conducted in the five intervention stores during the trial period, and staff surveys and stakeholder interviews were conducted in both the five intervention stores and the six wait-listed control stores after completion of the trial (May 2018) when both intervention and wait-listed control stores were self- maintaining the intervention. We used findings from customer surveys to develop methods for subsequent staff surveys, and then used customer and staff survey findings to develop interviews (explained in detail below).

Constructs for investigation and selection of measurement tools were informed by: established process evaluation frameworks including RE-AIM [16]; the Diffusion of Innovations theory [17] which describes how an idea or innovation is spread and adopted within a social system and characteristics of interventions likely to spread; Baranowski and Stables' methodological guide [6] to assessment of key process evaluation constructs; as well as the intervention's program logic model [13].

\section{Customer surveys \\ Overview}

Customer exit surveys were conducted at all five intervention stores approximately 6 months into the intervention (October 2017) to collect self-reported data on (i) intervention reach including customer demographics; (ii) recall of the intervention; (iii) perceptions of overall intervention, specific intervention components, and potential alternate or additional interventions (measured on seven-point Likert scales; 1 = 'strongly dislike', 7 = 'strongly like'); and (iv) perceptions of overall intervention and individual component effectiveness in promoting healthier choices. Survey questions were developed based on constructs relevant to the specific intervention components, informed by previous retail customer surveys [18], and adapted from questions successfully piloted in the three previous Eat Well @IGA short-term trials. See Additional file 1 for full customer survey. 


\section{Sampling and recruitment}

Exiting customers at the five stores who were aged 18 years or older and the main grocery buyer in their household were invited to self-complete the approximately 10-min, anonymous, paper-based survey. Sample size was decided based on pragmatic considerations and considering the primary purpose of the survey that was to provide feedback to the retailers on customer satisfaction and intervention component recall. A sample of 100 customers per intervention store was considered large enough to estimate the prevalence of binary outcomes with 95\% confidence intervals which in the worst case (50\% prevalence) would have a $20 \%$ total width.

\section{Analysis}

Customer perceptions of intervention components and suggestions for additional healthy food initiatives at the survey store were dichotomised for analysis due to extreme skewness of the distribution of the responses to many questions (1 to $4=$ unfavourable or neutral impression/ unsupportive or neutral support; 5 to $7=$ favourable impression/ supportive). Customer demographics were also dichotomised: age (18 to 54 years; 55 years and older), gender (male; female), area-based socioeconomic status according to postcode (Socio-Economic Indexes for Areas (SEIFA) Index of Relative Socio-Economic Disadvantage (IRSD)) [19] (lower half of SEIFA percentiles; upper half of SEIFA percentiles), educational attainment (less than university degree; university degree or higher), and frequency of customer visits (never, rarely or sometimes shop at survey store; always or usually shop at store). Heterogeneity of customer demographics across stores was assessed using the Chi-squared test. Overall proportion of customers in each demographic group (and 95\% CI), and associations between customers' perceptions and customer demographic variables were estimated using mixed-effects logistic models with the demographic variable as a fixed effect and store as random effect to account for the clustering induced by store. The intracluster correlation coefficient (ICC) is reported as a measure of variability of customer recall across stores.

Results at $p<0.05$ were considered statistically significant. Stata version 15 was used for all analyses.

\section{Staff survey \\ Overview}

Anonymous staff surveys were self-completed in August 2018, 3 months after the end of the RCT intervention period during the retailer-led maintenance period to (i) investigate staff involvement with and attitudes towards the intervention, and (ii) assess perceptions of customer response to the intervention. Surveys took approximately 10 min to complete and included closed-ended and free- text questions on personal demographics, interactions with customers, and attitudes towards the overall intervention and its specific components. Questions from the full questionnaire are mapped to these concepts and to Baranowski and Stable's process evaluation framework [6] in Additional file 2.

\section{Sampling and recruitment}

All staff within all 11 stores (including the 5 intervention and 6 wait-listed control stores) were eligible to participate. After receiving consent from store managers, flyers were displayed in staff rooms and/or notice boards inviting staff to complete the paper-based survey.

\section{Analysis}

Descriptive statistics were used to summarise findings and inform development of stakeholder interview questions.

\section{Stakeholder interviews Overview}

The first author (MRB) conducted semi-structured interviews with stakeholders from intervention and selected wait-listed control stores at 15-17 months following the start of the RCT (August to October 2018, during the retailer-led maintenance period in intervention and wait-listed control stores). Stakeholders were defined as those involved in co-designing and managing the intervention, and those responsible for intervention implementation. Interviews aimed to explore (i) stakeholder perceptions of the Eat Well @IGA intervention; (ii) factors which enabled or inhibited intervention implementation and may affect maintenance and scalability; and (iii) explanations for customer and staff survey findings.

\section{Interview questions}

The 30-60-min interviews focused on interview participant roles, intervention advantages, disadvantages, barriers, enablers and sustainability, stakeholder communication, and potential improvements for the Eat Well@IGA intervention. Interview questions were developed by the research team to address key concepts of the Diffusion of Innovations theory [17] and RE-AIM framework [16]. Questions are mapped to these concepts in the full discussion guide (see Additional file 3). Questions were tailored to stakeholder roles.

\section{Sampling and recruitment}

Interviewees were purposively selected given their likely depth of knowledge regarding different components of the intervention, lines of communication and relationships between intervention partners (academic, retail, and government bodies) (see Additional file 4 for lines of communication) and selected to explore predicted 
causes of heterogeneity in implementation between stores (e.g., customer demographic composition). It was estimated that interviewing 15 to 20 key stakeholders would cover the breadth and depth of perceptions relating to the intervention. The interviewees comprised the local government officer responsible for research-retailer liaison, one supermarket group marketing manager, the main store group chief executive officer, all RCT intervention store managers (five), two store managers from highest and lowest SEIFA control stores, four grocery and fresh produce department managers from intervention stores with the lowest and highest SEIFA, three researchers (research lead; the data manager; and a research assistant), and two store owners.

\section{Analysis}

Interviews were audio recorded and transcribed verbatim. Interview transcripts were sent to participants for verification; participants did not express any concerns and no changes were made. Inductive coding and a block and segment analysis approach were used to identify key interview themes and sub-themes using NVivo qualitative data management software [20]. Coding was initially completed by an experienced qualitative researcher (MRB). A subset of 11 interviews was independently cross-coded by a second experienced qualitative researcher (CZ), and both coders discussed findings to decide on final themes.

\section{Results}

\section{Customer surveys}

Five hundred customers completed surveys at the five intervention stores (range: 97-104 per store) in October 2017 (Table 1). Respondents were more likely to be female $(72 \%), 55$ years or older $(65 \%)$, have a higher areabased socioeconomic status (SEIFA) (61\%), and speak
English at home (100\%) compared to the Victorian population. Sixty-four percent of respondents always or usually did their main planned (e.g. weekly/fortnightly) shop at the survey store. There was heterogeneity across stores by whether customers conducted their regular weekly shop always or usually at the survey supermarket, educational attainment, and area-based socioeconomic groupings (SEIFA), reflecting the location of participating stores (all $p \leq 0.01$ ).

Thirty-three percent [95\%CI:23,44] of respondents recalled the Eat Well @IGA project brand overall when prompted (see Table 2). Generally, half or fewer respondents recalled each intervention component. The highest recall was for the healthy food posters (49\%[95\%CI:37, $61])$, and the lowest for social media (12\%[95\%CI:7,18]). Some customers reported that Health Star Rating (HSR) shelf tags $(49 \%[43,56])$, posters $(49 \%[95 \% \mathrm{CI}: 37,61])$, shelf signs $(29 \%[95 \% \mathrm{CI}: 30,43])$, and trolley and/or basket signs (18\%[95\%CI:14,23]), influenced their food choices. Of those who said that trolley and/or basket signs had influenced their purchases, 69\%[95\%CI:49,84] reported that signs increased purchases of foods which corresponded to the core food groups from The Australian Dietary Guidelines (grains; vegetables and legumes/ beans; fruit; lean meats and alternatives; and dairy and alternatives) [15]. ICC estimates for intervention component recall ranged from 0.009 (letterbox flyers) to 0.113 (staff $t$ shirts), suggesting variation across stores for some components (Additional file 5, Table S1).

Customer perceptions were generally skewed towards more favourable ratings, with all intervention components receiving median ratings of 5 or 6 out of 7 (Additional file 5, Table S2).

Respondents overwhelmingly agreed that IGA should continue its efforts to encourage healthy eating (97\%[95\%CI:93,99]) (Table S3). Three percent [95\%CI:1,

Table 1 Demographic characteristics of customer survey participants $(n=500)$

\begin{tabular}{|c|c|c|c|c|c|c|c|c|c|}
\hline \multirow[t]{2}{*}{ Characteristic } & \multicolumn{2}{|c|}{ Overall } & \multirow{2}{*}{$\begin{array}{l}\text { Store } 1 \\
(n=104)\end{array}$} & \multirow{2}{*}{$\begin{array}{l}\text { Store } \\
2(n=97)\end{array}$} & \multirow{2}{*}{$\begin{array}{l}\begin{array}{l}\text { Store } 3 \\
(n=101)\end{array} \\
\text { Proportion }\end{array}$} & \multirow{2}{*}{$\begin{array}{l}\text { Store } 4 \\
(n=100)\end{array}$} & \multirow{2}{*}{$\begin{array}{l}\text { Store } 5 \\
(n=98)\end{array}$} & \multirow{2}{*}{$\begin{array}{l}\text { Heterogeneity } \\
\text { across stores } \\
\text { ( } p \text {-value) }^{b}\end{array}$} & \multirow{2}{*}{$\begin{array}{l}\text { State of } \\
\text { Victoria } \\
(\%)\end{array}$} \\
\hline & $\mathrm{n}$ & $\begin{array}{l}\text { Estimated } \\
\text { percentage } \\
{[95 \% \mathrm{Cl}]^{a}}\end{array}$ & & & & & & & \\
\hline Female & 355 & $72[68,76]$ & 67 & 75 & 70 & 75 & 74 & 0.650 & $51.9^{c}$ \\
\hline Aged $55+$ years & 322 & $65[61,70]$ & 63 & 68 & 65 & 72 & 60 & 0.445 & $33.0^{c}$ \\
\hline High SEIFA ${ }^{d}$ & 284 & $61[16,93]$ & 7 & 92 & 93 & 10 & 89 & $<0.001$ & $\sim 50$ \\
\hline University degree or higher & 165 & $34[26,42]$ & 24 & 32 & 34 & 27 & 52 & $<0.001$ & $24.3^{c}$ \\
\hline $\begin{array}{l}\text { Regular weekly shop always } \\
\text { or usually at this store }\end{array}$ & 234 & $64[56,72]$ & 67 & 71 & 60 & 73 & 49 & 0.010 & $\mathrm{~N} / \mathrm{A}$ \\
\hline $\begin{array}{l}\text { Shop regularly at competitor } \\
\text { supermarket }\end{array}$ & 463 & $93[90,95]$ & 92 & 92 & 90 & 93 & 96 & 0.621 & $\mathrm{~N} / \mathrm{A}$ \\
\hline
\end{tabular}

$n=500$ customer surveys at the 5 intervention stores, range of 97 to 104 surveys per store. N/A data not available

${ }^{a}$ Estimated using univariate logistic models with store as random effect to account for the clustering induced by store. ${ }^{b}$ Chi-squared test of differences in proportions across stores; ' Persons 15 years and older; ${ }^{\mathrm{d}}$ SEIFA, Index of Relative Socio-Economic Disadvantage- Socio-Economic Indexes for Areas [19]. 'High' SEIFA reflects top half of Victorian SEIFA groupings 


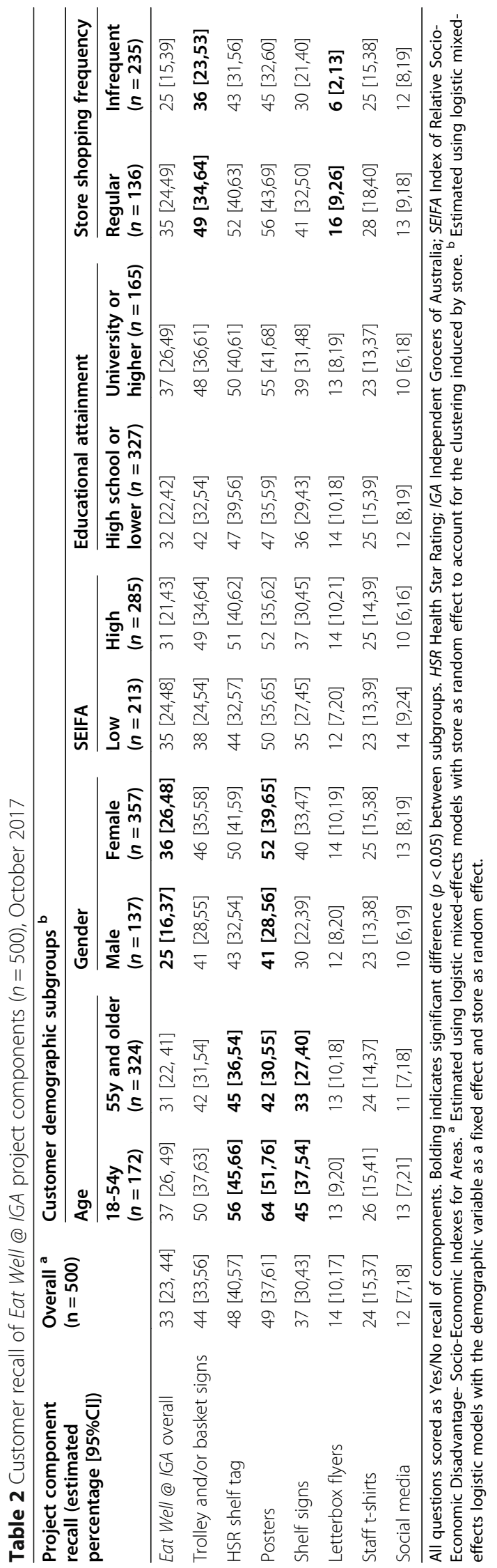


6] of respondents reported they were new customers to the store because of the intervention and $7 \%[95 \% \mathrm{CI}: 5,9]$ reported they had increased their shopping frequency at the store as a direct result of the intervention (only one customer reported they were shopping less frequently).

\section{Customer subgroup analyses results}

Customer subgroup analyses are reported in Table 2 and Additional file 5 (Tables S2 and S3). Respondents 55 years and older were less likely to recall Health Star Rating (HSR) shelf tags $(p=0.03)$, posters $(p<0.01)$, and shelf signs $(p<0.01)$. Compared to infrequent shoppers, regular shoppers were up to twice as likely to recall the project overall $(p=0.05)$, trolley and basket signs $(p=$ $0.03)$, shelf signs $(p=0.05)$ and letter box flyers $(p<$ 0.01 ). There was no difference in project or component recall between gender, educational attainment or Socioeconomic Index for Areas (SEIFA) levels (all $p>0.05$ ).

Respondents 55 years and older generally rated their perceptions of study components more highly than younger respondents (18 to 54 years) (Table S2). Female respondents gave higher ratings to the intervention overall as well as most components than male respondents, as did shoppers with higher compared to lower socioeconomic position (all $p<0.05$ ) (Table S2). Regular survey store shoppers rated all components more highly than infrequent shoppers (all $p \leq 0.03$ ), except floor signs $(p=0.09)$ and social media (Table S2). There was no difference in perceptions of project components by educational status. All subgroups had a mean of at least $94 \%$ support for IGA continuing its efforts to encourage healthy eating (Table S3). All subgroups had a mean of at least $75 \%$ support for new interventions of healthier products at the end of aisles and availability of healthy recipes in-store (Table S3).

\section{Staff surveys}

A total of 82 staff from 11 stores completed surveys in August to September 2018 (see Additional file 6, Table S4 for respondent demographics). No differences were found in staff characteristics between intervention and wait-listed control store surveys, hence we present overall results. The most frequent respondent role was department manager (29\%). Eighty percent of staff had been employed in their particular store for 2 years or more, meaning that they had been employed prior to the implementation of Eat Well @IGA. Most respondents (84\%) reported that they had not been directly involved with installation or maintenance of Eat Well @ IGA.

Staff had very favourable perceptions of Eat Well @ IGA overall (median $6[5,7]$ on 7-point Likert scale) and specific intervention components (see Additional file 6, Table S5). The most frequently cited components that "worked well" were trolley/ basket signs (27\% respondents), followed by HSR shelf tags (11\%) and floor sign (11\%), which staff reported to be the most noticeable by customers (Additional file 6, Table S6). The most frequently cited components that "did not work well" were the HSR shelf tags (17\% respondents), followed by shelf signs $(10 \%)$. The tags were noted to fall off easily. The shelf signs were noted to both fall off easily and get in the way of other products and signage (Additional file 6, Table S7). Most staff (78\%) had rarely or never received feedback from customers relating to EatWell @IGA or its components (Additional file 6, Table S8). The majority of feedback received, however, was very or slightly positive (e.g. "sending a positive message to customers"), or otherwise neutral (e.g. "[customer surprised] at the low star rating of products"). Only one respondent reported receiving "slightly negative" customer feedback, and none reported "very negative" feedback.

The majority of staff (93\%) thought Eat Well @IGA would be maintained at their store in the future. Reasons for thinking the intervention would not be maintained varied but comments included "It's not maintained now either", and that profit would be the main driver of supermarket strategies (e.g. "[price] specials sell first"). Respondents were asked to rank seven additional healthy eating strategies from least to most effective in terms of whether they would help customers make healthy choices (Additional file 6, Table S9). The highest median ranked option was "Price discounts on healthy foods and drinks" (2 [1, 3] out of 7). The lowest ranked was "One checkout that doesn't display unhealthy food" $(7[6,7])$.

\section{Stakeholder interviews}

Nineteen stakeholders participated in interviews between August and October 2018 (95\% response rate). Seventynine percent of interviewees were male, and all had been in their current role for at least 6 months. Below, key themes are discussed (theme and sub-theme names in italics). The themes encompass stakeholder perceptions of the intervention including factors which enabled or inhibited intervention implementation and may affect maintenance and scalability, as well as the perceived intervention outcomes. The interrelationship between these themes are shown in Fig. 2, with stakeholder collaboration and co-participation in planning, implementation and evaluation of the intervention (the "Co-design" approach) central to the project. A full table of themes and sub-themes is found in Additional file 7.

\section{Theme 1: Consider the influence of industry and public health context on intervention}

Interviewees described multiple contextual factors that influenced the implementation of Eat Well @IGA namely, the broader supermarket industry context 


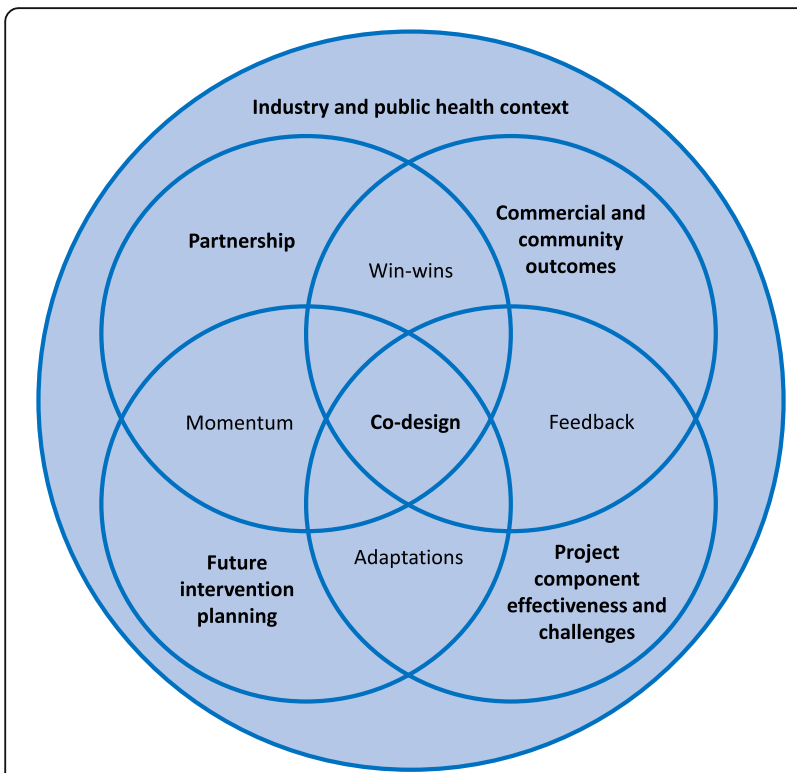

Fig. 2 Interrelationships between stakeholder interview themes on factors that were perceived to enable or inhibit the implementation, maintenance and scalability of Eat Well @ IGA, August to October 2018 ( $n=19$ interviews). Bolded text indicates main interview themes and unbolded text indicates interrelationships between themes

(defined as traditional business operations focused around sales and profitability) and the public health context (defined as the current health issues experienced by the target communities). Competing ideas and priorities were often alluded to as potential barriers and enablers to intervention implementation, within each of these sub-themes.

From an industry perspective, standard Supermarket operations were generally seen as a hindrance to implementing and sustaining healthy changes as business models tend to favour promoting sales of unhealthy foods and beverages because of perceived consumer demand and supplier contract agreements (e.g. Status quo is unhealthy; Power of conglomerates). However, broader Industry change was occurring in response to Customer trends towards healthy eating, particularly by healthconscious consumers and those with children; this increased the retailers' interest in implementing Eat Well @ IGA.

"I think the whole market's starting to change... people gravitating towards all those healthier type products. So I think within a couple of years, the demand for those products - well, it's already there now, but it's going to be even stronger." (Store Manager).

The public health benefit of promoting healthy eating through Eat Well @IGA was expressed by some store owners who viewed the intervention as Responding to community health needs based on their community context of poor health outcomes or deprivation:

"...our demographics around here, it's probably - if you just make people make one [healthier] choice differently, it's a winner that way." (Store Manager).

The researchers and local government research officer viewed the project as having a broader contribution to Public health advocacy beyond the immediate community, through the potential scale-up of Eat Well @ IGA through the IGA network and diffusion to other supermarket chains.

\section{Theme 2: Develop project partnership and align stakeholder objectives}

The Partnership, referring to the people and interpersonal relationships between academic, IGA, local government, and (to a lesser extent) external funder stakeholders, underpinned the conceptualisation, planning and implementation of the intervention. Partnership was more explicitly valued by those involved in setting up the intervention: the research lead and the local government research officer placed high emphasis on Stakeholder relationships being pivotal to the implementation and maintenance of Eat Well @ IGA, based on high levels of trust and Collaboration over several years. These stakeholders also placed greater emphasis on the Credibility of the project that was gained through local government and university participation, and government funding; and the necessity of Expertise in areas of nutrition and research (researchers), and supermarket operations (IGA executives). By contrast, store managers and department managers focused their discussions on the practicalities of day-to-day implementation of the intervention, although many acknowledged the practical and strategic value of the partnership. The Partnership was perceived by interviewees to be strengthened by Aligning stakeholder objectives - specifically relating to promoting healthy eating and business sales.

"One, the whole objective of the campaign was to try and influence or encourage people to eat healthier but also it was a win/win in the means of if we're selling more of those 4.5, 5 star [Health Star Rating] type products within our stores there's the potential of ... higher profit..." (IGA Executive).

\section{Theme 3: Co-design and collaborate for intervention design and progression}

Stakeholders were universal in their praise for the value of the process through which stakeholders in the Partnership (described above) collaborated and co- 
participated to design and progress the intervention, a process which we term "Co-design". For example, stakeholders described the productive process of working together in Planning and Selecting intervention components:

"So we sort of all sat down and discussed a range of options for what we could try in those stores and together we decided on the Health Star Rating shelf tags, the trolley signs and...the floor signs." (Local Government Research Officer).

Timely Feedback was considered important to the supermarket executives to enable decision-making to proceed and to determine how the project should move forward, but this was limited by contrastingly long research timeframes in applying for Funding, and data analysis and publication.

\section{Theme 4: identify intervention component characteristics, effectiveness and challenges}

Stakeholders expressed mixed views when asked about the effectiveness, challenges and proposed modifications of specific project components. Store managers who believed that the intervention would be more effective appeared to be more engaged in intervention maintenance and scaleup. Comments on specific components were similar to staff survey feedback (see above). Participants most commonly proposed Modifications to overcome issues with Maintenance of HSR shelf tags. For example, in one store:

"they'd [the supermarket staff] basically made their own tape or data strip tape to actually sit inside [the shelf strips], ... a general Eat Well @ IGA one." (Researcher).

Other general concerns about intervention components included that the Salience of point-of-sale material decreases over time (in the context of ubiquitous marketing causing Visual noise in the supermarket):

"we sometimes use the term 'air pollution', because sometimes it's just too busy and people don't stop and read. But the baskets and the trollies; it's basically right in the customer's face." (Store Manager).

Several supermarket stakeholders recommended regularly refreshing the marketing material to maintain intervention effectiveness.

\section{Theme 5: Consider the commercial and community} outcomes

The main intervention outcomes raised by participants broadly fell into (i) commercial or profit-related outcomes, and (ii) community outcomes related to customer feedback and purchasing effects. Profit impact was generally predicted to be either neutral (given that supermarkets mostly Profit from unhealthy foods) or to slightly increase (as Profit margins are higher on healthy products including fresh produce).

"we've got to put a chocolate [on display at the checkout] because we've got to survive, we've got to make money to keep our staff employed and pay our bills." (IGA Executive).

Return on investment was a central consideration of executives and store owners for determining commercial viability of the intervention:

"the question for us as a business is what's it going to cost and then what's the return on it?" (IGA Executive).

Rather than direct profit returns, most returns were discussed in light of Competitive advantage by improving Corporate image and creating a point-of-difference among competitor supermarkets. The majority of investment/cost discussions related to staff Time as a resource to maintain the intervention, particularly the HSR shelf tags. Most store and department managers estimated 14 staff hours would be required to maintain the tags per month, although the perceived value of this time varied. A smaller sub-theme was Customer feedback. Customers were generally noted to have had a low awareness of the intervention and this therefore did not appear to affect intervention outcomes.

\section{Theme 6: Plan and adapt for the future using evidence and support}

When asked about the future sustainability and scalability of Eat Well @IGA, interviewees outlined the need for evidence, funding, practical support and improvements in some components. Stakeholders noted that Sustainability of the intervention in current stores and Scale-up to other IGAs or supermarket chains would need to be underpinned by Evidence of effectiveness (thought to be Uncertain prior to rigorous quantitative evaluation) and Ongoing modification to refine intervention components. The vast majority of intervention installation and maintenance was done or paid for by the researchers. Some supermarket and non-supermarket interviewees expressed concern that removal of this assistance would make intervention Sustainability less likely. Scale-up was almost universally seen as desirable, but limited by some concerns that without researcher or other central oversight it would not be enforced or implemented 'correctly' to improve the healthiness of 
customer choices, rather than as a marketing tool to create a perception of being a healthier place to shop compared to competitors.

"I think if the results come back are good and everything's positive I think the potential's huge more so from a macro or IGA brand." (IGA Executive)

\section{Discussion}

This process evaluation of the complex supermarket intervention Eat Well @IGA demonstrated that it had high support from customers, staff and broader stakeholders. Key learnings included barriers around staff time required for intervention maintenance and perceptions of reduced salience of the intervention over time among customers due to the ubiquitous marketing noise in the modern retail environment. The collaborative partnership and co-participation between stakeholders what we have termed "co-design" - was a key enabler of planning, implementation and future directions of the project.

Findings from this study align with previous evaluations of supermarket and grocery store interventions [11], including the identification of staff time as a key barrier to sustainability $[9,21]$. Our stakeholder interviews have extended these previous studies by revealing that these concerns persisted at 12 months. Key concerns related to the opportunity cost of staff time (i.e. staff time spent on Eat Well @ IGA instead of other projects) and the expected return on investment of the time and effort involved in intervention implementation, rather than the financial cost or number of staff hours required per se, which was estimated around $1-4 \mathrm{~h}$ per month.

Our use of the Diffusion of Innovations theory [17] and Baranowski and Stables' process evaluation guide [6] in survey and interview question design helped to provide insights into whether or not Eat Well @IGA embodied the usual characteristics of scalable innovations. For example, interviewees expressed conflicting views on the Diffusion of Innovation [17] characteristic of "compatibility" of the intervention with status quo supermarket operations. On the one hand, most stakeholders acknowledged that status quo operations tend to favour unhealthy foods and beverages. On the other hand, some stakeholders including retailers expressed hope that it might address perceived increasing consumer demand for healthier supermarket offerings. Senior IGA stakeholders discussed advantages (e.g. potential profit increases) and disadvantages (e.g. increased staff time) of the intervention in relation to current practice (described by the Diffusion of Innovations theory as "Relative advantage" [17]). Future monitoring of IGA networks will be required to determine whether Eat Well @IGA does in fact diffuse to other IGA stores.

Low customer recall of the Eat Well @IGA brand (33\% [95\%CI:23, 44]) and project components was indicated by both customer surveys and noted in some stakeholder interviews. Staff survey results suggested that salience of the intervention decreased over time. As such, promotional material may need to be periodically refreshed to remain effective and to cut-through the visual noise in the supermarket [22]. The issue of salience decreasing over time has not been a key finding of other relevant process evaluations, perhaps due to the shorter timeframe of previous evaluations, and the modest size of the current merchandising-based intervention. Alternatively, the effectiveness of the intervention may not just depend on recall, but rather the intervention may work by a variety of psychological mechanisms. For example, many of the trolley and shelf signs targeted social norms around healthy eating. Future healthy food retail interventions that utilise marketing messages should plan for regularly refreshing campaign materials, while considering intervention cost and sustainability, and targeting different psychological pathways of effect.

Another novel component of our evaluation was examination of variation in customer recall and perceptions of components across stores. We found moderate variation in recall across stores, which may reflect extent of implementation. Higher recall of HSR shelf-tags, posters and shelf-signs was found among younger compared to older respondents in the customer survey. This may be related to age-related cognitive declines in attention, and aligns with stakeholder interviews which suggested that younger, health-conscious consumers (especially those with young families) engaged more with the project.

We found customers demonstrated extremely high self-reported support for Eat Well @IGA and further changes to improve the healthiness of the in-store supermarket environment; however, staff and stakeholders reported limited customer feedback (positive or negative). A recent review of business outcomes in healthy food retail initiatives found that $65 \%$ of measured customer perception outcomes were favourable [18]. While customer perceptions were not a focus of stakeholder interviews, positive impacts on brand image [9] were central to supermarket stakeholder's assessment of commercial viability. This was aligned with the IGA chain brand slogan "how the locals like it" and supermarket stakeholders' references to industry growth in healthy food sales in Australia, which has also been recently identified in interviews with US supermarket retailers [21].

Customers expressed support for other potential changes to encourage healthier purchases, including healthier end of aisle displays and the availability of 
healthy recipes. This is consistent with other evaluations of similar interventions [10, 11]. Accordingly, these intervention components should be considered as part of future initiatives. Nonetheless, there are likely to be important barriers to implementing these suggestions as end of aisle displays are frequently dictated by contractual agreements with manufacturers, as highlighted by several interviewees.

The most important intervention outcomes specified by interviewees varied according to retailer role, with store staff focusing on staff resourcing needed for dayto-day intervention maintenance, and store managers and executives focused on community health outcomes and brand image. The strongest support for Eat Well @ IGA was expressed by stakeholders who prioritised the value of the intervention on community health outcomes. Whether the staff from smaller, communitybased supermarkets such as IGA rate community health and goodwill more highly than staff from larger chain supermarkets (who often have less direct relationships with their local community) could not be determined in the current study. Moreover, suppliers were not identified by interviewees as a key barrier to implementation, despite being raised in previous interviews with supermarket [21] and small grocery store managers [23]. This was likely because the current intervention did not involve changes in product placement or availability.

Considerable emphasis was placed on the value of the co-design approach between retailers, government and academic partners by those directly involved in the project development. Perceived advantages included the diverse attributes that different partners brought to the project including the credibility provided by local government and university participation, government funding, nutrition and research skills, and supermarket operations knowledge. Consistent with other community health promotion partnerships, our stakeholders identified challenges of academic and funding timelines [24], but also the dividends including sustainability brought by time investment in partnerships. Our findings were also in line with other supermarket-academic partnerships which have noted that co-design elements in planning, implementation and evaluation have been essential to programme sustainability [25].

There was strong support among the three main stakeholder groups (local government, supermarket, academic partners) for the partnership and Eat Well @IGA to continue, provided modifications were made regarding HSR tags and refreshing of the materials, which could otherwise hinder intervention uptake. Some supermarket senior stakeholders required a profit increase directly attributable to the intervention to continue to support the project, while for most a neutral sales effect was sufficient given the perceived benefits to brand image and community wellbeing. There was uncertainty among interviewees about what the next steps should be, noting organisational and resourcing difficulties with scale-up to other IGAs. A 2016 systematic review found no evidence examining the scale-up of a supermarket intervention [3]; addressing this gap will be critical to increasing the population impact of healthy food retail initiatives, which must be maintained long-term across many settings to drive meaningful population health changes.

\section{Strengths and limitations}

This research used a theory-driven $[6,16,17]$ sequential mixed-methods design to examine a complex supermarket intervention from the complementary perspectives of different stakeholders. Demonstrating the value of the mixed-methods approach, qualitative and quantitative data sources were sometimes concordant (e.g. customer intervention recall), and at other times discordant (e.g. customer intervention support in customer surveys was not reflected in staff surveys). The 12-month time frame of the intervention provided a longer-term perspective on maintenance and sustainability of supermarket initiatives. Views of customers and staff surveyed may not be representative of the target population groups, as it is possible those who had more extreme views (positive or negative) were more likely to respond to surveys. Although we did not have data on all customer demographics, we found that surveyed customers tended to be older and to have a higher socioeconomic position than the general population (and therefore likely customers overall). The views of stakeholders may also change over time, noting that some stakeholders (retail and other) had been involved in healthy eating initiatives for up to 4 years prior to this evaluation. Repeated longitudinal assessment of the opinions of retail stakeholders throughout all phases of the intervention process would be of interest in future initiatives.

\section{Conclusions}

This process evaluation of the 12-month Eat Well @ IGA supermarket RCT found that the retailer-academicgovernment partnership and co-design process was critical for the development and maintenance of this intervention. These findings are an important accompaniment to the outcome data on the effectiveness of the intervention, and will aid in interpretation of those findings. Our learnings emphasised the importance of limiting retailer time and costs and the need for periodic refreshment of point-ofsale marketing materials to maintain customer salience. Identifying and implementing factors that lead to longterm sustainable and widespread healthy supermarket initiatives is critical to realising the potential population health benefits of healthy supermarket initiatives. 


\section{Abbreviations}

HSR: Health Star Rating; ICC: Intra-cluster correlation coefficient: IGA: Independent Grocers of Australia; IRSD: Index of Relative SocioEconomic Disadvantage; RCT: Randomised Controlled Trial; SEIFA: SocioEconomic Indexes for Areas

\section{Supplementary Information}

The online version contains supplementary material available at https://doi. org/10.1186/s12966-021-01104-z.

Additional file 1. Customer survey questions. Full list of customer survey questions.

Additional file 2. Supermarket staff survey questions. Full list of staff survey questions and target construct(s) per question.

Additional file 3. Stakeholder interview discussion guide. Stakeholder interview discussion guide and target construct(s) per question.

Additional file 4. Stakeholder roles and lines of communication. Figure showing lines of communications between different stakeholders, their places within organisations and main organisational roles.

Additional file 5. Customer survey detailed results. Detailed customer survey results including tabulated overall and subgroup analyses and text descriptions.

Additional file 6. Staff survey detailed results. Detailed staff survey results including tabulated overall and subgroup analyses.

Additional file 7. Stakeholder interview themes, sub-themes and illustrative quotes. Stakeholder interview themes, sub-themes and illustrative quotes.

\section{Acknowledgements}

Store managers, staff and leaders from participating IGA stores across Victoria; research assistants including Winsfred Ngan, Tom Steele, Christine Walters, Jasmine Noske, and Anna Paix; City of Greater Bendigo; Prof Boyd Swinburn for his helpful feedback on the manuscript.

\section{Authors' contributions}

AJC, GS, AKB, LO, JA, MM, CNM, and FE contributed to the design of the Eat Well @IGA intervention. MRB and AJC conceived the process evaluation. $\mathrm{MRB}, \mathrm{AJC}, \mathrm{GS}$, and $\mathrm{AKB}$ contributed to the design of the process evaluation. $J M$ and AJC coordinated customer survey collection. MRB collected the staff survey and interview data. CZ, LO and MRB analysed the data. MRB wrote the paper. AJC oversaw the Eat Well @ IGA evaluation. All authors revised and approved the final manuscript.

\section{Funding}

This work was supported by a National Health and Medical Research Council (NHMRC) Partnership Project Grant including financial and in-kind contributions from VicHealth and Deakin University (https://researchdata.ands.org.au/ multi-component-supermarket-healthy-eating/948754) [including support of MRB], salary support for MRB through a Deakin University Institute for Health Transformation Post-doctoral Fellowship and in-kind support from IGA and the City of Greater Bendigo. The funding body was not involved in the design of the study or collection, analysis, interpretation of data or in writing the manuscript. MRB, AJC, GS, LO, JA, MM, and CNM are researchers within the National Health and Medical Research Council (NHMRC) funded Centre of Research Excellence in Food Retail Environments for Health (RE-FRESH) (APP1152968). The opinions, analysis, and conclusions in this paper are those of the authors and should not be attributed to the NHMRC

\section{Availability of data and materials}

The data from the anonymous staff and customer surveys are available from the authors on reasonable request. The interview data are not publicly available due to containing sensitive personal information.

\section{Declarations}

\section{Ethics approval and consent to participate}

Ethics approval for this study, including interviews, staff and customer surveys was provided by Deakin University Faculty of Health Human Ethics Advisory Group, reference number HEAG-H 65_2015. Interview participants gave written informed consent and anonymous customer and staff survey respondents gave implied consent to participate.

\section{Consent for publication}

Not applicable.

\section{Competing interests}

The authors declare that they have no competing interests. IGA supermarket did not provide funding support for this trial.

\section{Author details}

${ }^{1}$ Deakin University, Geelong, Global Obesity Centre, Institute for Health Transformation, Locked Bag 20000, Victoria 3220 Geelong, Australia. ${ }^{2}$ Biostatistics Unit, Deakin University, Locked Bag 20000, Geelong, Victoria 3220, Australia. ${ }^{3}$ City of Greater Bendigo, PO Box 733, Bendigo, Victoria 3552, Australia. ${ }^{4}$ Deakin Health Economics, Institute for Health Transformation, Faculty of Health Deakin University, Locked Bag 20000, Geelong, Victoria 3220, Australia. ${ }^{5}$ National Institute for Health Innovation, University of Auckland, Private Bag 92019, Auckland 1142, New Zealand. ${ }^{6}$ Paris School of Economics and INRA, 48, Boulevard Jourdan, 75014 Paris, France.

Received: 30 November 2020 Accepted: 25 February 2021

Published online: 12 March 2021

\section{References}

1. Kantar Worldpanel. A global view on changing trade dynamics. London: Kantar Worldpanel; 2017.

2. Hawkes C. Dietary implications of supermarket development: a global perspective. Dev Policy Rev. 2008;26(6):657-92.

3. Cameron AJ, Charlton E, Ngan WW, Sacks G. A systematic review of the effectiveness of supermarket-based interventions involving product, promotion, or place on the healthiness of consumer purchases. Curr Nutr Rep. 2016:5(3):129-38.

4. Ball K, McNaughton SA, Le HN, Gold L, Mhurchu CN, Abbott G. Influence of price discounts and skill-building strategies on purchase and consumption of healthy food and beverages: outcomes of the supermarket healthy eating for life randomized controlled trial. Am J Clin Nutr. 2015;101(5):1055-64.

5. Ni Mhurchu C, Blakely T, Jiang Y, Eyles HC, Rodgers A. Effects of price discounts and tailored nutrition education on supermarket purchases: a randomized controlled trial. Am J Clin Nutr. 2010;91(3):736-47.

6. Baranowski T, Stables G. Process evaluations of the 5-a-day projects. Health Educ Behav. 2000;27(2):157-66.

7. Stirman SW, Kimberly J, Cook N, Calloway A, Castro F, Charns M. The sustainability of new programs and innovations: a review of the empirical literature and recommendations for future research. Implement Sci. 2012; 7(1):17.

8. Olstad DL, Ball K, Abbott G, McNaughton SA, Le HN, Ni Mhurchu C, et al. A process evaluation of the supermarket healthy eating for life (SHELf) randomized controlled trial. Int J Behav Nutr Phys Act. 2016;13:27

9. Steenhuis I, van Assema P, Reubsaet A, Kok G. Process evaluation of two environmental nutrition programmes and an educational nutrition programme conducted at supermarkets and worksite cafeterias in the Netherlands. J Hum Nutr Diet. 2004;17:107-15.

10. Ferguson M, O'Dea K, Holden S, Miles E, Brimblecombe J. Food and beverage price discounts to improve health in remote Aboriginal communities: mixed method evaluation of a natural experiment. Aust N Z J Public Health. 2017;41(1):32-7.

11. Phipps EJ, Braitman LE, Stites SD, Singletary SB, Wallace SL, Hunt L, et al Impact of a rewards-based incentive program on promoting fruit and vegetable purchases. Am J Public Health. 2015;105(1):166-72.

12. Eat Well @ IGA Melbourne, Australia: Deakin University; 2018 [cited 2019 Jan 10]. Available from: https://www.eatwellatiga.com.au.

13. Blake MR, Sacks G, Marshall J, Brown AK, Cameron AJ. The Eat Well @ IGA healthy supermarket project: A successful seven-year collaboration between 
a supermarket chain, local government, non-government organisation, and academic researchers. 2021. In: the handbook of health promotion research [accepted 20/02/2021] [internet]. UNESCO Chair in Global Health \& Education.

14. Department of Health. Health Star Rating System Canberra, Australia: Australian Department of Health; 2019 [cited 2019 Jan 10]. Available from: http://healthstarrating.gov.au/.

15. National Health and Medical Research Council. Australian Dietary Guidelines. Canberra: NHMRC; 2013.

16. Glasgow RE, Vogt TM, Boles SM. Evaluating the public health impact of health promotion interventions: the RE-AIM framework. Am J Public Health. 1999;89(9):1322-7.

17. Rogers EM. Diffusion of innovations. 5th ed. New York: Free Press; 2003.

18. Blake MR, Backholer K, Lancsar E, Boelsen-Robinson T, Mah C, Brimblecombe $J$, et al. Investigating business outcomes of healthy food retail strategies: a systematic scoping review. Obes Rev. 2019;20(10):1384-99.

19. Australian Bureau of Statistics. Socio-Economic Indexes for Areas Canberra, Australia: ABS; 2011 [updated 27 Mar 2018; cited 2019 Jan 8]. Available from: http://www.abs.gov.au/.

20. NVivo Qualitative Data Analysis Software. 11 ed. Melbourne, Australia: QSR International Pty Ltd; 2016.

21. Martinez O, Rodriguez N, Mercurio A, Bragg M, Elbel B. Supermarket retailers' perspectives on healthy food retail strategies: in-depth interviews. BMC Public Health. 2018;18(1):1019.

22. Milliron BJ, Woolf K, Ruhs B, Appelhans B. Establishing a universitysupermarket partnership for healthier shopping. Gateways. 2012;5(1):183-91.

23. Ayala GX, D'Angelo H, Gittelsohn J, Horton L, Ribisl K, Sindberg LS, et al. Who is behind the stocking of energy-dense foods and beverages in small stores? The importance of food and beverage distributors. Public Health Nutr. 2017;20(18):3333-42.

24. Strong LL, Israel BA, Schulz AJ, Reyes A, Rowe Z, Weir SS, et al. Piloting interventions within a community-based participatory research framework: lessons learned from the healthy environments partnership. Prog Community Health Partnersh. 2009;3(4):327-34.

25. Escaron AL, Martinez-Donate AP, Riggall AJ, Meinen A, Hall B, Nieto FJ, et al. Developing and implementing "Waupaca eating smart": a restaurant and supermarket intervention to promote healthy eating through changes in the food environment. Health Promot Pract. 2016;17(2):265-77.

\section{Publisher's Note}

Springer Nature remains neutral with regard to jurisdictional claims in published maps and institutional affiliations.

Ready to submit your research? Choose BMC and benefit from:

- fast, convenient online submission

- thorough peer review by experienced researchers in your field

- rapid publication on acceptance

- support for research data, including large and complex data types

- gold Open Access which fosters wider collaboration and increased citations

- maximum visibility for your research: over $100 \mathrm{M}$ website views per year

At BMC, research is always in progress.

Learn more biomedcentral.com/submissions 